\title{
Efficiency and sustainability assessment for a group of farmers in the Brazilian Amazon
}

\author{
Eliane Gonçalves Gomes • João Carlos Correia Baptista Soares de Mello • \\ Geraldo da Silva e Souza • Lidia Angulo Meza • \\ João Alfredo de Carvalho Mangabeira
}

Published online: 24 June 2008

(C) Springer Science+Business Media, LLC 2008

\begin{abstract}
The aim of this paper is to use DEA models to evaluate sustainability in agriculture. Several variables are taken into account and the resulting efficiency is measured by comparison. The performance of family farms is analysed here (variables: farmed area, work force, and production). As agricultural sustainability depends on the maintenance of systems of production for long periods of time, the models were run for the years of 1986 and 2002. Tiered DEA models were used to group farmers in sustainability categories. Non-parametric regression models were used to identify the factors affecting the efficiency measurements. All the results indicate that the majority of the farmers increased their efficiency along the time. These improvements may support the existence of sustainability.
\end{abstract}

Keywords Data envelopment analysis · Iso-efficiency tiers · Regression · Family farms

E.G. Gomes $(\bowtie) \cdot$ G.S. e Souza

Brazilian Agricultural Research Corporation (Embrapa), Parque Estação Biológica, Av. W3 Norte final, 70770-901, Brasília, DF, Brazil

e-mail: eliane.gomes@embrapa.br

G.S. e Souza

e-mail: geraldo.souza@embrapa.br

J.C.C.B. Soares de Mello

Production Engineering Department, Fluminense Federal University, Rua Passo da Pátria 156,

24210-240, Niterói, RJ, Brazil

e-mail: jcsmello@pesquisador.cnpq.br

L. Angulo Meza

Material Science Department, Fluminense Federal University, Av. dos Trabalhadores 420, 27255-125,

Volta Redonda, RJ, Brazil

e-mail: lidia@pq.cnpq.br

J.A.C. Mangabeira

Embrapa Satellite Monitoring, Av. Dr. Júlio Soares de Arruda 803, 13088-300, Campinas, SP, Brazil

e-mail: manga@cnpm.embrapa.br 


\section{Introduction}

Sustainability of farming systems has been historically dependent on constant productivity for long periods of time. During the last decades, sustainability has become a variable that needs to be analysed and measured (Carpenter 1993). In agriculture, sustainability involves physical, biotic, economic feasibility and socio-cultural factors. We can mention, for instance, Von Wirén-Lehr's (2001) work on the sustainable agriculture theme.

There are several approaches in the literature to evaluate agricultural sustainability. The majority proposes building up multidimensional indicators. These can be aggregated in a unique "sustainability index" that evaluates the performance of the productive system. The following related works should be mentioned: Ali (1996), Pannell and Glenn (2000), Rigby et al. (2001), Praneetvatakul et al. (2001), López-Ridaura et al. (2002), Herendeen and Wildermuth (2002), Lopes and Almeida (2003), Zhen and Routray (2003), Pacini et al. (2003), Fernandes (2004), Rasul and Thapa (2004).

Some authors have proposed the use of DEA models to measure agricultural sustainability as, for instance, Kim (2001), De Koeijer et al. (2002), Abay et al. (2004), RodríguezDíaz et al. (2004), Bosetti and Locatelli (2006), Sauer and Abdallah (2007). These studies are briefly described in Sect. 2.3.

The purpose of this paper is to use Data Envelopment Analysis (DEA) to evaluate the sustainability of a group of farmers. This approach was chosen as the resulting efficiency has two basic characteristics: it is measured by comparison and it allows different variables to be taken into account. The first one allows farmer's performance to be compared with itself at different instants. The efficiency variation along the time can be used as an indication of sustainability. The multidimensional characteristic of the DEA approach is relevant as sustainability involves multiple factors. In this paper we use a DEA model to analyse the socio-agronomic performance of a farmers' group. Farmed area, work force and production were the variables used to do so. The farmers are located in the municipality of Machadinho d'Oeste (State of Rondônia, Brazil).

The concept of agricultural sustainability used here requires that production systems be maintained for large periods of time. To check whether agricultural sustainability applies, two different DEA models were run separately for both the years of 1986 and 2002. Afterwards a third DEA model was run using the data for 1986 and 2002 put together. This last model aims to check whether or not the positive evolution of the average efficiency is relevant as an indication of sustainability. This kind of analysis is one of this study's main contributions.

Our second contribution is related to the use of the Tiered DEA model. The tiers obtained with this model have been used as a ranking tool (Barr et al. 2000), which in a multicriteria terminology is a $P \alpha$ problem (Roy and Bouyssou 1993). The tiered DEA model has also been used to group the units under evaluation into clusters, each cluster corresponding to one tier (Soares de Mello et al. 2005). Once more, using the multicriteria terminology this is similar to the $P \beta$ problem. In this paper we used the Tiered DEA model to group farmers into sustainability clusters. As many tiers were obtained we need to group them in order to obtain a final ranking, as will be explained in Sect. 4.2.

The last contribution of this paper refers to the case study itself. The municipality of Machadinho d'Oeste is an agricultural settlement in the Brazilian Amazon. The Brazilian Agricultural Research Corporation (in Portuguese, Empresa Brasileira de Pesquisa Agropecuária-Embrapa) has been conducting a long-term study in the region. Its Satellite Monitoring Research Centre (Embrapa Satellite Monitoring for short) is responsible for this research. The research began some twenty years ago and is supposed to be an one hundred years study of smallholdings in that region (Miranda 2005). The considerable amount 
of the data obtained from field research may be used to generate several socio-agronomic indexes. Among those are the ones pertaining to its agricultural sustainability. According to Miranda (2005), this information may influence public policy for the region in terms of support, research, financing and others.

We may also refer that, although a lot of research has been done concerning Machadinho d'Oeste, this is the very first one in which DEA efficiency models are used. The use of DEA models to evaluate efficiency in agriculture in the Brazilian Amazon was found only once in Otsuki et al. (2002). This study has used public data instead of data obtained from field research. Furthermore, the authors were not concerned with sustainability studies. Their main goal was the study of the effects caused by the Brazilian governments' ownership granting policies based on the efficiency of agricultural and timber production in the region.

\section{Data envelopment analysis (DEA)}

\subsection{General features}

DEA models have been originally proposed by Charnes et al. (1978) to determine the efficiency of productive units, known as Decision-Making Units (DMU for short). These models take into account the resources used by the DMUs and the results they obtain. DEA models optimise the efficiency index of each individual DMU in order to estimate an efficient piecewise linear frontier. These DMUs become the benchmarks for the inefficient ones.

The two best-known DEA models are CCR (Charnes et al. 1978) and BCC (Banker et al. 1984). Traditionally, two different orientations are possible for these models when looking for the efficient frontier: input orientation and output orientation. The first one aims to promote DMU efficiency by an equiproportional reduction of the inputs levels. On the other hand, the aim of output orientation is to promote DMU efficiency by an equiproportional increase of the output levels.

There are two equivalent mathematical formulations for each DEA model. The first one is called the multipliers model and the second one is the envelope model. There is a dual relationship between these two models. From the multipliers model we obtain the efficiency index and the multipliers (weights) for each variable. From the envelopment model we also obtain the efficiency index. Moreover, this model also provides benchmarks and targets for each inefficient DMU.

Their proprieties must be known to model in DEA and interpret their results correctly. Two of the most important properties are as follows:

1. In any DEA model, every DMU that presents the best output $j /$ input $i$ ratio is necessarily efficient. This requires the causal relation between each output and each input to be checked in any DEA formulation. If this relation does not exist, meaningless results may appear. In other words, a badly formulated model might show a DMU to be efficient, for instance, based on its coffee production (output) in relation to its rice growing area (input), which is obviously nonsensical.

2. The main property of the CCR model is the proportionality between inputs and outputs at the frontier. This means that any increase (decrease) in the value of the inputs corresponds to a proportional increase (decrease) in the value of the outputs. 
Fig. 1 Tiered DEA model

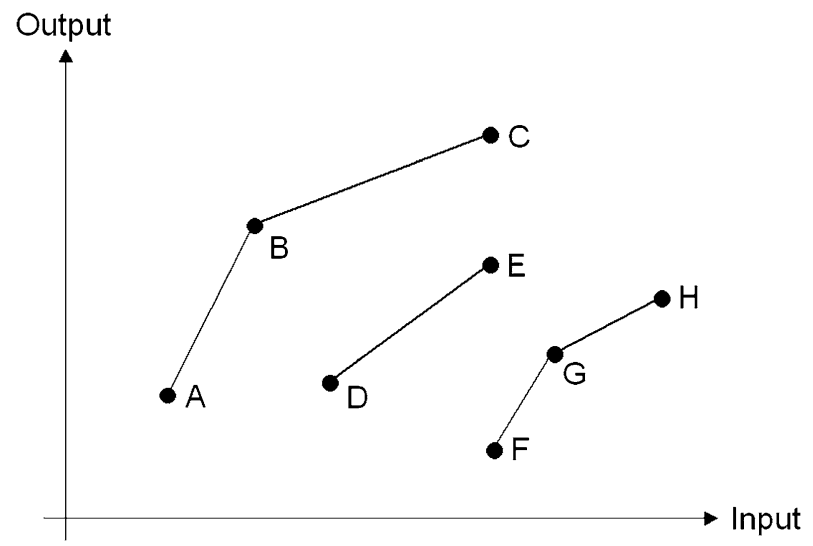

\subsection{Tiered DEA models}

DMUs can be grouped into efficiency categories. They could subjectively be classed as having low, middle or high efficiency, for instance. Another alternative is to class them according to the so-called iso-efficiency tiers.

This model was initially proposed by Barr et al. (2000) and is called "Tiered DEA". The authors have used this approach as an auxiliary tool to obtain an alternative DEA ranking. Gomes et al. (2003) used this approach to establish sequential targets and promote frontier uniformity in Zero Sum Gains DEA models (Lins et al. 2003; Gomes and Lins 2008). Bougnol and Dulá (2006) contend that this technique can be used to class DMUs into groups according to their performance level.

Iso-efficiency tiers are obtained thus: $100 \%$ efficient DMUs belong to tier 1 . These DMUs are then withdrawn from those being analysed and a new DEA model is run. Efficient DMUs in this subset belong to tier number 2. The process is repeated until there are no further DMUs.

Figure 1 shows this technique. As the DEA model was run with all the eight DMUs, A, $\mathrm{B}$ and $\mathrm{C}$ were $100 \%$ efficient and so they belong to tier 1 . The withdrawal of these DMUs leaves another five DMUs. Running the DEA model again with these five DMUs, D and E are efficient and they belong to tier 2. These are withdrawn and the DEA model is run again with the remaining three DMUs $(\mathrm{F}, \mathrm{G}$ and $\mathrm{H})$. All were efficient and so they make up the third and last iso-efficiency tier.

\subsection{DEA models and agricultural sustainability}

In the literature there are some studies concerning the use of DEA models to analyse agricultural sustainability. The focus of those papers is the environmental consequences of the inputs use. This is rather different from our focus. We use in this paper a concept of sustainability that relates to the capacity of the production systems to be maintained along the time. Some of the above mentioned papers are briefly described herebelow.

Kim (2001) compared the scale efficiency scores of conventional and sustainable farms. The analysis included DEA CCR and BCC models efficiency calculations. The author found that sustainable farms had more profitable input/output relationship than conventional farms.

Later on, De Koeijer et al. (2002) have measured sustainability based on socio-economic and bio-ecological attributes. The authors have used DEA models to measure the sustainability of a group of Dutch sugar beet growers over four consecutive periods of time. The 
authors assume sustainability as being a mix of environmental efficiency plus economic performance. In their words "if farmers improve the technical efficiency of their use of polluting inputs, they simultaneously achieve economic and environmental objectives". That means that improvements of technical efficiency may support sustainability.

In another work, Abay et al. (2004) analysed DEA CCR efficiency measurements of input use in tobacco production in Turkey with respect to sustainability. The authors carried out face-to-face interviews with some 300 farmers. They also developed econometric models to determine the factors affecting the efficiency of the regional tobacco production. The results showed a positive relationship between the efficiency of input use and sustainability of agriculture.

Rodríguez-Díaz et al. (2004) used DEA BCC models to evaluate which were the most efficient irrigation districts in Andalusia (Spain) relative to water use. The authors believed that the study of efficiency allows them to assess when the use of water leads to greater profitability. Hence, the results may help to improve water management.

Bosetti and Locatelli (2006) studied the relative efficiency of the management units of Italians national parks and showed how it could be improved. The variables (indicators) used were based on Italian national park managers and stakeholders opinions.

Sauer and Abdallah (2007) studied tobacco production in Tanzania. The authors were looking for the existence of empirical relations among production efficiency, biodiversity, and resource use. The results suggested that an increase in tobacco production efficiency is conducive to environmental sustainability in Tanzania.

\section{Characterization of the target area}

Machadinho d'Oeste is a municipality in the State of Rondônia belonging to the Brazilian Amazon. It is located between longitude $61^{\circ} 47^{\prime}$ and $63^{\circ} 00^{\prime} \mathrm{WGr}$ and between latitude $9^{\circ} 19^{\prime}$ and $10^{\circ} 00^{\prime} \mathrm{S}$, some 400 kilometres from Porto Velho, the state capital.

Before becoming a municipality in 1988, Machadinho d'Oeste started as a rural settlement project. The new municipality included 4 other settlement projects and 8 urban centres and covered an area of $8,556 \mathrm{~km}^{2}$. Studies covering several aspects of this area can be found, for instance, in Moran (1984), Sydenstricker and Torres (1991), Castilla and Sawyer (1993), Dale et al. (1994), Charlwood et al. (1996), Souza-Santos (2002), Miranda (2005).

The Machadinho settlement project was initially dimensioned for 3,000 families. More than 2,000 had already arrived in 1984 . The project already had in that year the minimal infra structures for an agricultural settlement such as roads, urban support nuclei, zoning and plot demarcation etc.

From the very beginning of the settlement in the early 80 's, the original landscape has been modified by settlers into a mosaic of forest patches, secondary vegetation, and grazing, agricultural and small urban areas. In Batistella et al. (2000, 2003) and Batistella (2001), studies can be found on land use and land cover changes in Machadinho d'Oeste.

In 1986, a research project was launched to follow the agricultural production systems used by the small farmers of the area (Miranda 2005). Fieldwork is done every three years, using questionnaires with some 250 agricultural, social, economical and environmental variables covering a sample of farms. Every year land use is monitored by satellite images in a Geographic Information System (GIS).

In the first year of the research, 1986, a large sample, covering $15 \%$ of a total of 438 valid plots was taken. This random and stratified sample was codified in a GIS folder. The results of this first data survey in situ defined the initial profile of the just arrived farmers and their agriculture. 
A new survey, in 1989, created a GIS folder, which profiled the area and its farmers. In 1993, research work also included economic and environmental data. The 1996 field survey showed that in ten years deep changes had occurred in the farms.

The 1999 fieldwork covered 438 farmers. These fieldworks provide an update on the farmers' profiles. From September to October of 2002, a new survey was carried out. In this survey only 327 farmers were interviewed. The 2005 fieldwork updated these data.

Miranda (2005) published all the results of the above-mentioned research. During this period, the region has dramatically changed in social and economical contexts as well as in land use. The changes concerning the farmers' performance are evaluated in this paper with the aid of DEA models. The results obtained are used to analyse the existence of sustainability in the production process.

\section{Modelling}

\subsection{Structuring}

The aim of the proposed DEA models is to measure sustainability in agriculture. Agricultural sustainability as used here means the farmers being able to keep on using their production systems. Thus, the DMUs are the farmers included in the 1986 and 2002 fieldwork samples.

Only those that were in both samples (a total of 76) were studied. Abandoned plots or those that had changed hands were not taken into account, as different farmers have different agricultural rationalities that could interfere in the evaluation.

Selecting variables in DEA is of great importance as final analysis depends on them. To evaluate agricultural sustainability the variables were chosen from those collected in the field questionnaires. In the model proposed here, there was an attempt to measure socioagronomic performance. In this model, inputs are area under cultivation (in hectares) and labour (in man-days); outputs are the various productions (in kilograms). In the extreme case of the model, if, for a given DMU, a zero weight is assigned to the area input, the efficiency measurement is the usual labour productivity. Similarly, should the zero weight be assigned to the labour input, then classical land productivity is obtained. Thus, the complete model is an optimised mix of these two agricultural productivity measurements.

To obtain more meaningful results, only values for the most important crops in the region were selected. The sole perennial crop of any significance is coffee. Among the annual crops, rice and maize are the most important. Thus, the variables of the DEA model are the following:

- Input 1: total rice, maize and coffee cultivated area equals the sum of all these cultivated areas;

- Input 2: labour used for rice, maize and coffee crops equals the sum of labour used in individual plots;

- Output 1: rice production;

- Output 2: maize production;

- Output 3: coffee production.

This model measures the ability to get a good production, with existing inputs, for at least one crop. The use of the total land and total labour prevents DMUs from being classed as efficient just because there is a good ratio between the production of one crop and the inputs of another, as explained before. 
Table 1 Condensed description of variables

\begin{tabular}{|c|c|c|c|c|c|c|}
\hline & & \multicolumn{2}{|l|}{ Inputs } & \multicolumn{3}{|l|}{ Outputs } \\
\hline & & $\begin{array}{l}\text { Crop } \\
\text { area }\end{array}$ & Labour & $\begin{array}{l}\text { Rice } \\
\text { production }\end{array}$ & $\begin{array}{l}\text { Maize } \\
\text { production }\end{array}$ & $\begin{array}{l}\text { Coffee } \\
\text { production }\end{array}$ \\
\hline \multirow[t]{2}{*}{1986} & Average & 6.3 & 253.9 & $1,520.5$ & $1,219.9$ & 0.0 \\
\hline & $\begin{array}{l}\text { Relative } \\
\text { frequency }(\%)\end{array}$ & 100.0 & 100.0 & 47.4 & 26.3 & 0.0 \\
\hline \multirow[t]{2}{*}{2002} & Average & 8.2 & 479.5 & $2,004.2$ & $2,515.8$ & $4,229.8$ \\
\hline & $\begin{array}{l}\text { Relative } \\
\text { frequency (\%) }\end{array}$ & 100.0 & 100.0 & 31.6 & 25.0 & 80.3 \\
\hline
\end{tabular}

The selected crops represent the main growing options in the region, or, in other words, they are the main food staples (maize and rice for self-consumption) or commercial crop (coffee). In this model, efficient farmers are those that succeed in sustaining their activity.

Labour was defined as all family members between ages 15 to 65 effectively employed in agricultural work, as well as permanent and temporary workers. In Machadinho d'Oeste, a rural worker works, on average, 300 days in agriculture. The labour ratios per crop in Machadinho d'Oeste are the following: rice, 19 man days per hectare; maize, 15 man days per hectare; coffee, 67 man days per hectare.

It should be emphasised that the use of fertilisers, pesticides, weed killers and similar were not taken into account in this model. In fact, most agriculture in Machadinho d'Oeste is practically carried out without these agricultural inputs, as they are expensive in this region. In other words it is a labour intensive system, not a capital intensive one. Other costs of production were not included either, as they are not included in the fieldwork questionnaires.

The DEA BCC model was chosen for this paper. This is justified, as there is no evidence that in Machadinho d'Oeste increases in area or in labour would cause a proportional increase in production. Input orientation was chosen to check whether production justifies the used resources or not. It should be emphasised that both inputs can be controlled. As a matter of fact, having less temporary workers or fewer member of the family working the land can reduce labour. In the same way, cultivated area can be decreased by selling parts of it or by preserving native scrubs. This would be important to diminish the problem of scrub area loss in the Brazilian Amazon region.

Table 1 shows the average values and relative frequency for inputs and outputs in the model. Relative frequency means the ratio between the number of plots with a non-zero value for the variable to which the frequency refers and the total number of plots.

\subsection{Sustainability typologies}

To define sustainability typologies, a DEA model was run for each of the years being studied. So, a given farmer could belong to one typology in one year and to another one in the other year. A farmer's efficiency index can improve from one year to another for two different reasons. The first is that there was a genuine improvement on his/her performance. The second one is that overall performance of all farmers decreased. In this case the improvement on the farmer efficiency index merely states that he/she worsened less than the others did.

\subsubsection{DEA BCC results analysis}

To calculate the efficiency indexes we have used the SIAD software (Angulo-Meza et al. 2005). Of the 76 evaluated plots, 10 were DEA-BCC efficient in 1986 and 12 in 2002. 
Of these, only three farmers were efficient in both years. Average efficiency in 1986 was 0.3166 and 0.3904 in 2002 . It should be made clear that although average efficiency is widely used in literature (see Avkiran 1999, for instance) its increase does not mean a general improvement in the DMUs evaluation. It means only a greater homogeneity among the whole set of DMUs under evaluation. This could have come about either because inefficient DMUs became more efficient or, else, because efficient DMUs became less so.

The three efficient farmers in both years (two from the State of Rio Grande do Norte, one from the State of Minas Gerais) arrived in Machadinho d'Oeste during the seventies. In 1986 each cultivated 9 hectares. Two of the farmers had already used technical assistance institutions and hired no permanent labour in their farms. All the three farmers had identified lack of finance and labour as problems in 1986 and health as a requirement. In 2002, one of these farmers belonged to a trade union. They identified health and lack of road as problems and housing as a requirement. In that year, the area cultivated by those farmers was, on average, $47 \%$ of the farm total area; two used technical assistance from Emater (Technical Assistance and Rural Support Company).

A preliminary analysis of the multipliers model showed that in 1986,9 plots $(11.8 \%)$ and 22 plots $(28.9 \%)$ do not take into account, respectively, the cultivated area and use of labour inputs to compute the measurement of efficiency. In the case of outputs, $41(53.9 \%)$, $55(73.4 \%)$ and $76(100 \%)$ plots have assigned zero weight respectively to rice, maize and coffee production. This analysis is preliminary, as the set of multipliers may not be unique. The values mentioned hereabove are the first ones calculated by the software we have used. This paper did not go further on multiplier analysis (for instance those carried out by Rosen et al. 1998 or by Soares de Mello et al. 2002).

A similar analysis was done for 2002. This analysis showed that the same proportion of plots as in 1986 did not take cultivated area into account to measure efficiency. On the other hand, the number of plots that assigned a nil weight to labour went up to 64 (84.2\%). This means that labour may well become the limiting factor for the socio-agronomic sustainability in Machadinho d'Oeste. This confirms that the agricultural activity in this municipality is labour intensive. When looking at the outputs, rice, maize and coffee production obtained a zero weight in, respectively, $55(72.4 \%), 45(59.2 \%)$ and $15(19.7 \%)$ of the plots. We should emphasise the small number of nil weights in coffee production. This has become the main crop of the region between 1986 and 2002. Coffee has a great selling potential. On the other hand, the two other cultures, rice and maize, were used for farmers' self-consumption in most cases.

The envelope model showed that in 1986 one efficient DMU turned into a benchmark for $60.5 \%$ of the inefficient DMUs. This was a farmer from the Amazon State living in the area since 1961 . He cultivated $10 \%$ of his lot and had employed neither temporary nor permanent labour. All his family worked on the farm.

Similarly, in 2002, another efficient DMU became the benchmark for $72.4 \%$ of the inefficient ones. This farmer came from the Bahia State in 1981. In 2002 he cultivated 29\% of his farm whole area. Likewise, he employed neither temporary nor permanent labour and all his family worked the land.

\subsubsection{Tiered DEA results analysis}

Iso-efficiency tier approach was employed to rank farmers as already described in Sect. 2.2. Seventeen iso-efficiency tiers were found for 1986 and eleven tiers were found for 2002 (individual DEA models) as per Table 2.

Although a bi-univocal correspondence between tiers and typologies could be used, the number of tiers is too high to be useful. It should be brought to mind that Saaty (1994) 
Table 2 Iso-efficiency tiers and sustainability typologies

\begin{tabular}{|c|c|c|c|c|c|c|c|}
\hline \multicolumn{4}{|l|}{1986} & \multicolumn{4}{|l|}{2002} \\
\hline Tiers & $\begin{array}{l}\text { No. of } \\
\text { DMUs }\end{array}$ & $\begin{array}{l}\text { Average } \\
\text { efficiency }\end{array}$ & Typologies & Tiers & $\begin{array}{l}\text { No. of } \\
\text { DMUs }\end{array}$ & $\begin{array}{l}\text { Average } \\
\text { efficiency }\end{array}$ & Typologies \\
\hline 1 & 10 & 1.0000 & Excellent & 1 & 12 & 1.0000 & Excellent \\
\hline 2 & 10 & 0.5582 & Medium & 2 & 16 & 0.5010 & Medium \\
\hline 3 & 10 & 0.3295 & & 3 & 9 & 0.3848 & \\
\hline 4 & 10 & 0.2056 & Low & 4 & 12 & 0.2132 & \\
\hline 5 & 7 & 0.1419 & & 5 & 6 & 0.1748 & Low \\
\hline 6 & 7 & 0.1344 & & 6 & 2 & 0.1553 & \\
\hline 7 & 4 & 0.0932 & Critical & 7 & 3 & 0.1294 & \\
\hline 8 & 3 & 0.0850 & & 8 & 6 & 0.1382 & \\
\hline 9 & 2 & 0.0875 & & 9 & 5 & 0.0989 & Critical \\
\hline 10 & 3 & 0.0729 & & 10 & 3 & 0.0519 & \\
\hline 11 & 2 & 0.0594 & & 11 & 2 & 0.0827 & \\
\hline 12 & 1 & 0.0477 & & & & & \\
\hline 13 & 2 & 0.0372 & & & & & \\
\hline 14 & 1 & 0.0312 & & & & & \\
\hline 15 & 2 & 0.0268 & & & & & \\
\hline 16 & 1 & 0.0164 & & & & & \\
\hline 17 & 1 & 0.0130 & & & & & \\
\hline
\end{tabular}

requires the decision-maker to take into account no more than 5 judgement differences, accepting up to nine only in extreme cases. So, 17 and 11 tiers are both too high a number for differences to be spotted. For that reason, we made the option of aggregating tiers. We first calculated the average efficiency for each and every tier. Then, when we found a large difference between two consecutive tiers, a typology was defined. What a large difference is understood to be is a subjective evaluation of the authors. This subjective component of the analysis makes this problem very close to the $P \beta$ multicriteria problem (Roy and Bouyssou 1993). Then, four types of sustainability were established (Table 2): Excellent, Medium, Low and Critical. These results show a decrease in the number of sustainability critical farms and an increase in those of medium and excellent typology. 47.4\% improved their typology, $25.0 \%$ worsened it and $27.6 \%$ remained constant. They also showed that a majority of farmers increased their sustainability. However, as said before, this may just mean that the efficient farmers have worsened their performance. To know exactly which of the outcomes really happened, a new model that aggregates the two periods of time in one single analysis is required.

\subsection{Time evolution}

To check whether the growth in the average efficiency in 2002 was due to an improvement in the performance of the farmers, a further analysis was carried out. In this third model, the same farmer was assumed to be two different DMUs in two different years. This approach is similar to that of Rios and Maçada (2006). In this BCC input oriented model there are 152 DMUs. This is justified, as the farmers' technology has apparently not evolved 
far enough (Miranda 2005). We would need to use instead the Malmquist index (Färe and Grosskopf 1992), for instance, if it had.

Using this model we found 19 DMUs to be efficient. All DMUs that were efficient in 2002 in the individual model were also efficient in this third model. In 1986, 7 of the 10 efficient DMUs in the individual model were also efficient in the aggregate model. For DMUs corresponding to the year of 1986 the average efficiency was 0.2788 . For DMUs in 2002, the average efficiency was 0.3573 . Those results clearly indicate the contention that there was an actual improvement in the farmers' performance between 1986 and 2002. So the evolution of the average efficiency in the partial models corresponds to an overall better performance of the whole set of DMUs.

As discussed by De Koeijer et al. (2002), the increase in efficiency shows sustainability. Thus, according to this contention, it can be said that the farmers of Machadinho d'Oeste showed a positive performance, and that means sustainability.

\subsection{Factors affecting efficiency}

A regression model was used to find out the factors that affected efficiency between 1986 and 2002. DEA efficiency indexes became the dependent variables for both years. One can find similar examples of this type of analysis in the literature. We can refer to, for instance, Kirjavainen and Loikkanen (1998), Otsuki et al. (2002), Casu and Molyneux (2003), Afonso and St. Aubyn (2006), Souza (2006) and Hoff (2007), who have all used the Tobit model. Sohn (2006) has used the Logit regression. Recently, Souza et al. (2007) have used Dynamic Panel Data to explain that contextual variables do affect DEA efficiency indexes.

As, in our case, the dependent variable values go from 0 to 1 a non-parametric regression model was used to evaluate causal relationships. The theoretical justification for this type of analysis can be found in Banker (1993), Banker and Natarajan (2004, 2008) and Souza (2006). Furthermore, the non-parametric regression is easier than its alternatives: truncated regressions and their generalizations (Souza 2006). Besides, it requires less restrictive hypotheses for the residual distribution.

As suggested by Conover (1999), efficiency rankings were used for the non-parametric approach. Ranks were computed for the combination of the samples obtained for each year.

We have fitted the analysis of covariance model (1) to the ranking structure. The independent variables used there have the following meanings.

Lot ownership status refers to the legal provisions affecting the farmer's lot: the two levels are "secure" and "precarious". Secure applies to farmers who own the plot of land. Precarious means he is entitled to its use but that he is not the owner.

Agricultural technical advice refers to whether or not the farmer has received technical support from Emater, the official body that provides such advice in the country.

Unworked days refer to the total number of days the farmer could not work on his farm because of illness. This variable can provide information on the municipality health care policies.

The total area variable is the sum of all areas in the plot of land: crop, pasture, fallow and wild areas.

Levels throughout the formula are either/or conditions represented by 1 or 2 .

In this model, $r_{i j k l}$ is the rank of the efficiency measurement for DMU $i, i=1, \ldots, 76$, in year $j, j=1,2$, subject to level $k, k=1,2$, for the type of plot ownership, to level $l$, $l=1,2$, for the existence of agricultural technical advice; $\mu$ is the general ranking average for the remainder number of units that are supposed to generate the readings; $\tau_{j}$ is the $j$ year effect; $\beta_{i}$ is the DMU $i$ effect; $d_{k}$ is the plot ownership effect at level $k ; e_{l}$ is the technical 
Table 3 Model significance

\begin{tabular}{lrllll}
\hline Source & DF & Sum of squares & Mean square & $F$ value & $\operatorname{Pr}>F$ \\
\hline Model & 80 & 190561.4185 & 2382.0177 & 1.67 & 0.0142 \\
Error & 71 & 101185.5815 & 1425.1490 & & \\
Corrected total & 151 & 291747.0000 & & & \\
\hline
\end{tabular}

Table 4 Non-parametric model results

\begin{tabular}{lrccr}
\hline Source & DF & Mean square & $F$ value & $P r>F$ \\
\hline Year & 1 & 7302.6895 & 5.12 & 0.0267 \\
DMU & 75 & 2387.9256 & 1.68 & 0.0147 \\
Unworked days & 1 & 4074.3817 & 2.86 & 0.0953 \\
Lot ownership status & 1 & 6440.1305 & 4.52 & 0.0370 \\
Technical assistance & 1 & 3164.6324 & 2.22 & 0.1406 \\
Total area & 1 & 623.0341 & 0.44 & 0.5106 \\
\hline
\end{tabular}

assistance effect at level $l$; $u w d_{i j k l}$ shows the number of unworked days and $t a_{i j k l}$ the total area for the observed DMU. Components $\varepsilon_{i j k l}$ are non-observable errors. Quantities $\mu, \tau_{j}$, $\beta_{i}, d_{k}, e_{l}, \theta, \pi$ are unknown parameters

$$
r_{i j k l}=\mu+\tau_{j}+\beta_{i}+d_{k}+e_{l}+\theta u w d_{i j k l}+\pi t a_{i j k l}+\varepsilon_{i j k l}
$$

The SAS v9.1.3 software and the PROC GLM procedure analyzed statistically the model. Tables 3 and 4 show its results. Table 3 shows the importance of the non-parametric model. The analysis of the individual effects shows the significance of the DMU, year and lot ownership $(<0.05)$ and the small significance of unworked days (0.095). Total area and technical assistance variables did not show any significant impact. Rank analysis shows efficiency growth in the period and the positive effect of plot ownership. On the other hand, a small negative effect of technical assistance was noticeable. This may either show inadequacy of the technical assistance programmes or farmers' difficulty in absorbing them. Meaningful scale effect, as measured by total area, was not noticed.

The education effect was thoroughly checked as well. Intuition would suggest that the better the farmer's formal education the better should be his efficiency. However, surprisingly, this effect seemed not to be the result. Two causes are almost certainly responsible for this puzzling situation. It was almost impossible to dissociate formal education from other DMU intrinsic characteristics (farmer's propensity for illness, hard work, labour skills, and so on) and the fact that only two little differentiated formal education levels were in place: none at all and four elementary school years. The conjugation of both factors may render meaningless the influence of formal schooling.

Other linear model alternatives are of no interest as being either meaningless or leading to misrepresentation of the circumstances. Other variables without apparent connection to efficiency were studied: machinery, trade associations, rural credit, age, time devoted to the plot, other non-agricultural activities and type of infrastructure (housing, electric energy, water and others).

It should be noted that the model does not take into account the use of chemicals such as fertilizers, pesticides, herbicides and fungicides for the efficiency measurement. As said 
before, most agriculture in Machadinho d'Oeste is carried out without these agricultural means. The total average of farmers using them was about 3\% in 2002 (Miranda 2005). In 1986 the average was even lower.

\section{Conclusions}

This paper has endeavoured to be a contribution to the state of the art in the evaluation of sustainability in agriculture by proposing the use of DEA models and of the tiered DEA models in this field. This is of importance in the Brazilian case as only one reference of DEA use was found in the literature, relative to the Amazon basin.

Results show that the majority of farmers have succeeded to develop better production systems, which are, in other words, a guarantee of sustainability. Labour can be a limiting factor in maintaining socio-agronomic sustainability in Machadinho d'Oeste, as the model's results show that the amount of labour does not justify the production of rice, maize and coffee. Growing coffee is labour intensive, which decreases its production performance in conjunction with the other crops. It can, however, be helpful for socio-agronomic sustainability. The consolidation of perennial crops is a basic requirement to sustain the farms if some ecological measures are adopted. We can cite the well-known factors of shade created by native trees, and mineral restitution.

Looking at the benchmarks in each model, we come to the conclusion that farmers should employ his family as labour force. We have also come to the conclusion that is desirable to preserve more than two thirds of property with native forest, which is in accordance with the conclusions obtained by Schneider et al. (2002). Farmers with some 20 years of work in their property turn into benchmarks for others. In other words, agricultural policies for the municipality should emphasise familiar agriculture, forest preservation and long-term projects.

The third DEA model shows farmers' performance improves with time, meaning that agricultural sustainability is a fact in Machadinho d'Oeste. The non-parametric regression model suggests the same.

As far as the tiered DEA approach is concerned, it can be seen that there is a large difference between the Efficient and Medium tiers both in 1986 and 2002. This difference is far greater than the difference between Medium and Low tiers, also in both years. Furthermore, there is a significant amount of DMUs in the Critical tier, 22 farmers in 1986, which were gratefully reduced to 9 in 2002. These results show that inefficient farmers have a great potential to improve themselves. This is a mild way of saying that they are really rather inefficient.

The results of the regression analysis confirm the importance of ownership legalisation, as already noted by Otsuki et al. (2002). Although in a small way, the number of unworked days can affect production efficiency. Apparently, the total size of the property does not have any influence in efficiency. A surprising result is that technical support is not significant to improve efficiency.

According to these results we dare to suggest some guidelines for the agricultural policies in the region. The first and foremost is to make significant efforts to grant formal ownership rights to all farmers. The number of unworked days caused by illness suggests that public health policies in the region must be looked into. Technical assistance policies must be revised as well: either they are not adequate to this type of farming or farmers are not educated enough to use the techniques proposed by authorities. Long-term policies are also of great import. 
Acknowledgements The authors gratefully acknowledge the financial support given by the National Council for Scientific and Technological Development (CNPq), Brazil, and the data supplied by Embrapa Satellite Monitoring.

\section{References}

Abay, C., Miran, B., \& Gunden, C. (2004). An analysis of input use efficiency in tobacco production with respect to sustainability: The case study of Turkey. Journal of Sustainable Agriculture, 24, 123-143. doi:10.1300/J064v24n03_09.

Afonso, A., \& St. Aubyn, M. (2006). Cross-country efficiency of secondary education provision: A semiparametric analysis with non-discretionary inputs. Economic Modelling, 23, 476-491. doi:10.1016/j. econmod.2006.02.003.

Ali, M. (1996). Quantifying the socio-economic determinants of sustainable crop production: an application to wheat cultivation in the Tarai of Nepal. Agricultural Economics, 14, 45-60. doi:10.1016/ 0169-5150(95)01161-7.

Angulo Meza, L., Biondi Neto, L., Soares de Mello, J. C. C. B., \& Gomes, E. G. (2005). ISYDSIntegrated System for Decision Support (SIAD-Sistema Integrado de Apoio à Decisão): a software package for data envelopment analysis. Pesquisa Operacional, 25, 493-503. doi:10.1590/S010174382005000300011.

Avkiran, N. K. (1999). The evidence on efficiency gains: The role of mergers and the benefits to the public. Journal of Banking and Finance, 23, 991-1013. doi:10.1016/S0378-4266(98)00129-0.

Banker, R. D. (1993). Maximum likelihood, consistency and DEA: a statistical foundation. Management Science, 39, 1265-1273.

Banker, R. D., \& Natarajan, R. (2004). Statistical tests based on DEA efficiency scores. In W. W. Cooper, L. M. Seiford, \& J. Zhu (Eds.), Handbook on data envelopment analysis (pp. 299-321). New York: Kluwer International Series.

Banker, R. D., \& Natarajan, R. (2008). Evaluating contextual variables affecting productivity using data envelopment analysis. Operations Research, 56, 48-58. doi:10.1287/opre.1070.0460.

Banker, R. D., Charnes, A., \& Cooper, W. W. (1984). Some models for estimating technical scale inefficiencies in data envelopment analysis. Management Science, 30, 1078-1092.

Barr, R. S., Durchholz, M. L., \& Seiford, L. (2000). Peeling the DEA onion: Layering and rank-ordering DMUs using tiered DEA (Technical Report). Southern Methodist University.

Batistella, M. (2001). Landscape change and land-use/land-cover dynamics in Rondônia, Brazilian Amazon. $\mathrm{Ph} . \mathrm{D}$. Thesis, Indiana University, Bloomington, Indiana.

Batistella, M., Brondizio, E. S., \& Moran, E. F. (2000). Comparative analysis of landscape fragmentation in Rondônia, Brazilian Amazon. International Archives of Photogrammetry and Remote Sensing and Spatial Information Sciences, 33, 148-155.

Batistella, M., Robeson, S., \& Moran, E. F. (2003). Settlement design, forest fragmentation, and landscape change in Rondônia, Amazônia. Photogrammetric Engineering and Remote Sensing, 69, 805-812.

Bosetti, V., \& Locatelli, G. (2006). A data envelopment analysis approach to the assessment of natural parks' economic efficiency and sustainability. The case of Italian national parks. Sustainable Development, 14, 277-286. doi:10.1002/sd.288.

Bougnol, M. L., \& Dulá, J. H. (2006). DEA as a ranking tool: An application of DEA to assess performance in higher education. Annals of Operations Research, 145, 339-366. doi:10.1007/s 10479-006-0039-2.

Carpenter, R. A. (1993). Can sustainability be measured? Environmental Strategy, 5, 13-16.

Castilla, R. E. F., \& Sawyer, D. O. (1993). Malaria rates and fate: A socioeconomic study of malaria in Brazil (1993). Social Science and Medicine, 37, 1137-1145. doi:10.1016/0277-9536(93)90253-Z.

Casu, B., \& Molyneux, P. (2003). A comparative study of efficiency in European banking. Applied Economics, 35, 1865-1876. doi:10.1080/0003684032000158109.

Charlwood, J. D., Alecrim, W. D., Fe, N., Mangabeira, J. A. C., \& Martins, V. J. (1996). A field trial with Lambda-cyhalothrin (ICON) for the intra domiciliary control of malaria transmitted by Anopheles darlingi root in Rondônia, Brazil (1996). Acta Tropica, 60, 3-13. doi:10.1016/0001-706X(95)00092-S.

Charnes, A., Cooper, W. W., \& Rhodes, E. (1978). Measuring the efficiency of decision-making units. European Journal of Operational Research, 2, 429-444. doi:10.1016/0377-2217(78)90138-8.

Conover, W. J. (1999). Practical nonparametric statistics, 3rd ed. New York: Wiley.

Dale, V. H., O’Neill, R. V., Southworth, F., \& Pedlowski, M. (1994). Modeling effects of land management in the Brazilian Amazon settlement of Rondônia. Conservation Biology, 8, 196-206. doi:10.1046/j. 1523-1739.1994.08010196.x. 
De Koeijer, T. J., Wossink, G. A. A., Struik, P. C., \& Renkema, J. A. (2002). Measuring agricultural sustainability in terms of efficiency: the case of Dutch sugar beet growers. Journal of Environmental Management, 66, 9-17. doi:10.1006/jema.2002.0578.

Färe, R., \& Grosskopf, S. (1992). Malmquist productivity indexes and Fisher ideal indexes. Economic Journal, 102, 158-160. doi:10.2307/2234861.

Fernandes, L. A. O. (2004). The meaning of sustainability: searching for agri-environmental indicators. Ph.D. Thesis, University of Manchester, England.

Gomes, E. G., \& Lins, M. P. E. (2008). Modelling undesirable outputs with zero sum gains DEA models. Journal of the Operational Research Society, 59, 616-623. doi:10.1057/palgrave.jors.2602384.

Gomes, E. G., Soares de Mello, J. C. C. B., \& Lins, M. P. E. (2003). Busca seqüencial de alvos intemediários em modelos DEA com soma de outputs constante. Investigação Operacional, 23, 163-178.

Herendeen, R. A., \& Wildermuth, T. (2002). Resource-based sustainability indicators: Chase county, Kansas, as example. Ecological Economics, 42, 243-257. doi:10.1016/S0921-8009(02)00056-3.

Hoff, A. (2007). Second stage DEA: Comparison of approaches for modelling the DEA score. European Journal of Operational Research, 181, 425-435. doi:10.1016/j.ejor.2006.05.019.

Kim, J. M. (2001). Efficiency analysis of sustainable and conventional farms in the re public of Korea with special reference to the data envelopment analysis (DEA). Journal of Sustainable Agriculture, 18, 9-26. doi:10.1300/J064v18n04_04.

Kirjavainen, T., \& Loikkanen, H. A. (1998). Efficiency differences of Finnish senior secondary schools: An application of DEA and Tobit analysis. Economics of Education Review, 17, 377-394. doi:10.1016/ S0272-7757(97)00048-4.

Lins, M. P. E., Gomes, E. G., Soares de Mello, J. C. C. B., \& Soares de Mello, A. J. R. (2003). Olympic ranking based on a zero sum gains DEA model. European Journal of Operational Research, 148, 312322. doi:10.1016/S0377-2217(02)00687-2.

Lopes, S. B., \& Almeida, J. (2003). Methodology for comparative analysis of sustainability in agroforestry systems. Revista de Economia e Sociologia Rural, 41, 183-208. doi:10.1590/S010320032003000100005.

López-Ridaura, S., Masera, O., \& Astier, M. (2002). Evaluating the sustainability of complex socioenvironmental systems: the MESMIS framework. Ecological Indicators, 2, 135-148. doi:10.1016/ S1470-160X(02)00043-2.

Miranda, E. E. (2005). Sustentabilidade Agrícola na Amazônia-Machadinho d'Oeste. Embrapa Satellite Monitoring. http://www.machadinho.cnpm.embrapa.br. Accessed 12 Nov 2007.

Moran, E. F. (1984). Amazon basin colonization. Interciencia, 9, 377-385.

Otsuki, T., Hardie, I. W., \& Reis, E. J. (2002). The implication of property rights for joint agriculturetimber productivity in the Brazilian Amazon. Environment and Development Economics, 7, 299-323. doi:10.1017/S1355770X02000190.

Pacini, C., Wossink, A., Giesen, G., Vazzana, C., \& Huirne, R. (2003). Evaluation of sustainability of organic, integrated and conventional farming systems: a farm and field-scale analysis. Agriculture, Ecosystems and Environment, 95, 273-288. doi:10.1016/S0167-8809(02)00091-9.

Pannell, D. J., \& Glenn, N. A. (2000). A framework for the economic evaluation and selection of sustainability indicators in agriculture. Ecological Economics, 33, 135-149. doi:10.1016/S0921-8009(99)00134-2.

Praneetvatakul, S., Janekarnkij, P., Potchanasin, C., \& Prayoonwong, K. (2001). Assessing the sustainability of agriculture: a case of Mae Chaem Catchment, northern Thailand. Environment International, 27, 103-109. doi:10.1016/S0160-4120(01)00068-X.

Rasul, G., \& Thapa, G. B. (2004). Sustainability of ecological and conventional agricultural systems in Bangladesh: an assessment based on environmental, economic and social perspectives. Agricultural Systems, 79, 327-351. doi:10.1016/S0308-521X(03)00090-8.

Rigby, D., Woodhouse, P., Young, T., \& Burton, M. (2001). Constructing a farm level indicator of sustainable agricultural practice. Ecological Economics, 39, 463-478. doi:10.1016/S0921-8009(01)00245-2.

Rios, L. R., \& Maçada, A. C. (2006). Analysing the relative efficiency of container terminals of Mercosur using DEA. Maritime Economics \& Logistics, 8, 331-346. doi:10.1057/palgrave.mel.9100168.

Rodríguez-Díaz, J. A., Camacho-Poyato, E., \& López-Luque, R. (2004). Application of data envelopment analysis to studies of irrigation efficiency in Andalusia. Journal of Irrigation and Drainage Engineering, 130, 175-183. doi:10.1061/(ASCE)0733-9437(2004)130:3(175).

Rosen, D., Schaffnit, C., \& Paradi, J. C. (1998). Marginal rates and two dimensional level curves in DEA. Journal of Productivity Analysis, 9, 205-232. doi:10.1023/A:1018382904489.

Roy, B., \& Bouyssou, D. (1993). Aide multicritère à la décision: méthods et cas. Paris: Ed. Economica.

Saaty, T. L. (1994). The fundamentals of decision making and priority theory with the analytic hierarchy process. Pittsburgh: RWS Publication.

Sauer, J., \& Abdallah, J. M. (2007). Forest diversity, tobacco production and resource management in Tanzania. Forest Policy and Economics, 9, 421-439. doi:10.1016/j.forpol.2005.10.007. 
Schneider, R. R., Arima, E., Veríssimo, A., Souza Jr., C., \& Barreto, P. (2002). Sustainable Amazon limitations and opportunities for rural development. World Bank Technical Paper, 515, 1-56.

Soares de Mello, J. C. C. B., Lins, M. P. E., \& Gomes, E. G. (2002). Construction of a smoothed DEA frontier. Pesquisa Operacional, 22, 183-201. doi:10.1590/S0101-74382002000200006.

Soares de Mello, J. C. C. B., Gomes, E. G., Gomes, L. F. A. M., Biondi Neto, L., \& Angulo Meza, L. (2005). Avaliação do tamanho de aeroportos portugueses com relações multicritério de superação. Pesquisa Operacional, 25, 313-330.

Sohn, S. Y. (2006). Random effects logistic regression model for ranking efficiency in data envelopment analysis. Journal of the Operational Research Society, 57, 1289-1299. doi:10.1057/palgrave.jors. 2602117.

Souza, G. S. (2006). Significância de efeitos técnicos na eficiência de produção da pesquisa agropecuária. Revista Brasileira de Economia, 60, 69-86.

Souza, G. S., Gomes, E. G., Magalhães, M. C., \& Avila, A. F. D. (2007). Economic efficiency of Embrapa's research centers and the influence of contextual variables. Pesquisa Operacional, 27, 15-26. doi:10.1590/ S0101-74382007000100002.

Souza-Santos, R. (2002). Seasonal distribution of malaria vectors in Machadinho d'Oeste, Rondônia State, Amazon Region, Brazil. Cadernos de Saúde Pública, 18, 1813-1818.

Sydenstricker, J. M., \& Torres, H. G. (1991). Mobility of migrants: autonomy or subordination in the Amazon region? Revista Brasileira de Estudos de População, 8, 33-54.

Von Wirén-Lehr, S. (2001). Sustainability in agriculture-an evaluation of principal goal oriented concepts to close the gap between theory and practice. Agriculture, Ecosystems and Environment, 84, 115-129. doi:10.1016/S0167-8809(00)00197-3.

Zhen, L., \& Routray, J. K. (2003). Operational indicators for measuring agricultural sustainability in developing countries. Environmental Management, 32, 34-46. doi:10.1007/s00267-003-2881-1. 